\title{
Investigation of the Vibroacoustic Climate Inside the Buses Solaris Urbino 12 Used in Public Transport Systems
}

\author{
Z. DAMiJAn ${ }^{a, *}$, D. IwAŃSKI ${ }^{a}$ AND G. DAHLKE ${ }^{b}$ \\ ${ }^{a}$ AGH University of Science and Technology, Faculty of Mechanical Engineering and Robotics \\ Department of Mechanics and Vibroacoustics, al. A. Mickiewicza 30, 30-059 Krakow, Poland \\ ${ }^{b}$ Poznań University of Technology, Faculty of Management Engineering, Chair of Ergonomics \\ and Quality Engineering, Strzelecka 11, 60-965 Poznań, Poland
}

\begin{abstract}
Despite new technological solutions and attempts to improve the working conditions during the operation of vehicles, city bus drivers are still exposed to negative impacts of noise and vibrations, causing stress, increased fatigue and lead to numerous diseases. Therefore it seems merited to investigate the acoustic climate (i.e. acoustic phenomena caused by the sources of noise of vibrations in the function of time and space) and the working conditions during the operation of Solaris Urbino 12 vehicles, widely used in public transport systems. The main aim of the research was to show the influence of the 5 day, $8 \mathrm{~h}$ working week on selected psycho-physiological parameters on a driver's organism. It was assumed that the main aggravating factor of the driver's organism are vibroacoustics conditions of a work place. The results of this research will be presented in due course. This work presents the research on vibroacoustic climate in one of many city buses used - Solaris Urbino 12. Investigation of the vibroacoustic climate is the branch of environmental biophysics. The measurements, tests and analysis are genuine because they were carried out under real conditions, with passengers, in the long stretches of time and in the entire route of the vehicle. Presented results are very rarely reported in the literature.
\end{abstract}

PACS: 89.40.-a, 07.10.-h, 43.40.Lc, 07.64.+z

\section{Introduction}

In present times of growing urbanization man is forced to move a great deal. Ensuring the efficient transport systems for passengers becomes a major problem faced in big cities and metropolises. At the present stage of development of transport system, passengers tend to prefer public means of transport to individual vehicles. This tendency is well apparent in highly urbanized metropolises $[1,3]$.

City buses are most popular vehicles used in public transport systems in Poland. By choosing the public transport, the responsibility for transport safety is shifted onto the bus driver. However, passengers spend decidedly shorter time in a bus than the bus driver in his whole working day. That is why the driver is more exposed to negative impacts produced by the vehicle's motion. It is required, therefore, that the working conditions for drivers should be monitored on a regular basis. In order that they work safely, their working conditions should be as comfortable as possible, in terms of physical and psychical conditions and free from any nuisance [3-14].

Noise must be considered as one of the most arduous

* corresponding author; e-mail: damijan@imir.agh.edu.pl factors in the material work environment. Methods of fighting with noise are, among others, preventing a creation of harmful noise, weakening the spreading of noise and using personal protective equipment.

Depending on the potential hazard level, noise is classified as nuisance (but not producing any lasting damage to the human body) and harmful noise - producing long lasting effects or increasing the risk of their occurrence $[2,11-16]$.

All parameters discussed in this section, associated with exposure to noise at work, i.e. the maximal sound level A, peak sound level $\mathrm{C}$, equivalent sound level $\mathrm{A}$, sound exposure per a working day $(8 \mathrm{~h})$ are derivatives of the acoustic pressure.

Measurements data should be interpreted in the light of the regulations set forth in the Journal of Laws [29 August 2005 no. 157 , item 1318] having relevance to work safety in the conditions of exposure to noise and mechanic vibrations, which specify the admissible noise levels (Table I).

The impacts of vibrations might be analysed in terms of:

- values of parameters describing the vibrations (acceleration, acceleration amplitude, frequency, exposure time), 
Admissible noise levels.

\begin{tabular}{l|c|c|c|c}
\hline \hline $\begin{array}{c}\text { Groups } \\
\text { of workers }\end{array}$ & $\begin{array}{c}L_{\mathrm{Aeq}, \mathrm{T}} \\
{[\mathrm{dB}]}\end{array}$ & $\begin{array}{c}L_{\mathrm{EX}, 8 \mathrm{~h}} \\
{[\mathrm{~dB}]}\end{array}$ & $\begin{array}{c}L_{A \max } \\
{[\mathrm{dB}]}\end{array}$ & $\begin{array}{c}L_{\mathrm{c} \mathrm{peak}} \\
{[\mathrm{dB}]}\end{array}$ \\
\hline workers - total & 80 & 80 & 115 & 135 \\
underage workers & 80 & 80 & 110 & 130 \\
pregnant women & 65 & 65 & 110 & 130
\end{tabular}

- the point of transmission (whole-body or local vibrations),

- personal idiosyncrasy (physical and psychical features).

The human system from the point of view of a classic mechanics is a kind of a resilient system, thanks to which it fosters a passive defense against vibration and shaking effects. Subconscious muscle cramps, which occur as a result of low frequency vibrations, provide active protection. The most dangerous are resonance vibrations, i.e. such vibrations whose frequency equals to the free vibration frequency of individual organs of the human body.

Up to about $2 \mathrm{~Hz}$ (subrange of low frequencies up to $2 \mathrm{~Hz}$ ), a human system reacts as a compact mass. In such range of frequencies, there occur symptoms connected with a balance organ (labyrinth), manifesting themselves as so-called travel sickness. In the subrange of middle frequencies $(2-18 \mathrm{~Hz})$, from an analysis of the kinetic model, one can conclude that in this range of frequencies there are almost all resonance frequencies of the human organs. With the frequency equaling to $5 \mathrm{~Hz}$, there occurs a resonance of the whole body (deviations from this frequency stem from different masses of individuals). In frequency ranges from 10 to $12 \mathrm{~Hz}$ and $15-16 \mathrm{~Hz}$, there are free vibration frequencies of the main internal organs.

In the mid-range of higher frequencies $(18-100 \mathrm{~Hz}$ ), apart from the frequencies of free vibrations of smaller organs (for example, eye balls), the subjective feeling of vibration activity gets smaller. The higher the frequency, the bigger is the vibration energy absorption by the soft tissues of the body [2].

Vibrations in long-term work exposure influence on, among others on the osteoarticular, circular and muscular systems.

Changes in the osteoarticular system are brought up mainly due to vibration activity with frequencies lower than $30 \mathrm{~Hz}$. There are also known cases of disturbances in the osteoarticular system caused by vibrations of higher frequencies. Pathological changes observed in a human body take place generally near the place of operating vibrations. With the help of radiology, the following changes were observed: a deformation of joint spaces, a calcification of capsules articularis, changes of the periosteum, symptoms of the osseous necrosis, changes in osseous texture, and at times osseous breaks.

General vibrations, which are the ones transferred from the ground or the seat onto a body (for example, in cases of tractor drivers), with the frequencies ranging from 6 to
$12 \mathrm{~Hz}$ and amplitudes of dislocations at 3 to $5 \mathrm{~mm}$, cause changes along the spine within intervertebral joints.

Disorders in the circular system are usually triggered by vibrations with the frequencies above $30 \mathrm{~Hz}$. An initial reaction of the circular system to the activity of the vibrations is of a reflex type and is a manifestation of the central nervous system activation, with a special stimulation of the vegetative system. During a contact with frequencies of 70 to $200 \mathrm{~Hz}$ with an insignificant amplitude, a so-called vasoneurosis may occur. What is also observed is lowering blood pressure, lowering hand temperature, and slowing down of the speed a pulse wave spreads along large vessels.

Muscles are actively involved in vibration amortization. This involvement is accompanied by disorders in many organs and systems, which guarantee that muscles are provided properly with oxygen and nutritional substances, remove products of exercise metabolism etc. Low frequency vibration amortization is a complex process, which is about a cooperation of afferent and efferent ways of the urinary system. The involvement of the muscle system during vibrations may lead to changes in the bioelectrical muscle activity. This activity is dependent on the parameters of frequency vibrations, amplitude, velocity and acceleration. Short-term activities of low frequency vibrations activate the muscle activity, long-term ones may hamper them. With the frequency of about $50 \mathrm{~Hz}$ there occurs the maximum pitch of bioelectric activity.

In several countries regulations and relevant standards have been developed to assess the noise and vibration hazard.

In literature on the subject noise and vibration exposures are categorized into passive (whereby passengers are exposed) and active (driver's or machine operator's exposure). The hazard level is obtained by comparing the registered levels with the admissible values. As regards the operators' exposure, regulations relating to vibrations as nuisance should be treated as benchmarks [13]. Admissible vibration exposure levels are specified in the relevant regulations (Journal of Laws no. 217 of 18 December 2002, item 1833; Journal of Laws no. 212 of 28 October 2005 item 1769; Journal of Laws no. 157 of 19 August 2005 item 1318; Journal of Laws no. 136 of 25 July 2005 item 1145; Journal of Laws no. 127 of 10 August 2002 item 1092) whereas recommendations specifying the vibration nuisance criteria can be found in the literature on the subject and in technical standards. The methods of evaluating the vibration impacts are compiled in the standard PN-91/N-03152:

- spectral method - the impacts of the exposure to vibrations are evaluated based on the effective acceleration data obtained from spectral analysis of vibration signals in $1 / 3$ octave bands,

- weighted method - the impacts of the exposure to vibrations are evaluated based on the effective vibration acceleration data weighted in the frequency 
domain, obtained from direct measurements taken with the dedicated vibration measurement devices in accordance with the standard PN-91/N-01355,

- dosimetric method - the assessment of vibration exposure is based on the equivalent weighted value of acceleration in a vibration dose, measured using a dosimeter.

The present study uses the weighted method to evaluate the human exposure to vibrations. In accordance with the standard PN-91/N/01352 the measuring disc is mounted in the driver's seat. After the measurements, the data are further utilised to derive the equivalent weighted acceleration value in accordance with the procedure set forth in the standard. Thus obtained weighted acceleration data are compared to maximal admissible exposure levels specified in the Journal of Laws no. 212 of 28 October 2005, item 1769 (Table II). Maximal levels of exposure to mechanical vibrations for pregnant women are given in Journal of Laws no. 127 of 10 August 2002, item 1092

\section{TABLE II}

Admissible exposure to mechanical vibrations [source: $\left(^{*}\right)$ - Journal of Laws No. 212 of 28 October 2005 item 1769; (**) - Journal of Laws No. 114 item 545 with amendments: Journal of Laws 2002 No. 127, item 1092; $\left.{ }^{* * *}\right)$ - Journal of Laws of 5 July 2005, No. 136, item 1145].

\begin{tabular}{l|c|c}
\hline \hline \multicolumn{1}{c|}{ Type of vibration } & $\begin{array}{c}\text { Daily exposure } \\
\text { must not exceed }\end{array}$ & $\begin{array}{c}30 \mathrm{~min} \text { or shorter exposure } \\
\text { must not exceed }\end{array}$ \\
\hline $\begin{array}{l}\text { vibrations acting on the human } \\
\text { body via upper limbs }\left(^{*}\right)\end{array}$ & $2.8 \mathrm{~m} / \mathrm{s}^{2}$ & $11.2 \mathrm{~m} / \mathrm{s}^{2}$ \\
\hline whole-body vibrations $\left(^{*}\right)$ & $0.8 \mathrm{~m} / \mathrm{s}^{2}$ & $3.2 \mathrm{~m} / \mathrm{s}^{2}$ \\
\hline $\begin{array}{l}\text { vibrations acting on pregnant } \\
\text { women via upper limbs }(* *)\end{array}$ & $1 \mathrm{~m} / \mathrm{s}^{2}$ & $4 \mathrm{~m} / \mathrm{s}^{2}$ \\
\hline $\begin{array}{l}\text { whole-body vibrations } \\
\text { acting on pregnant women }\end{array}$ & $\begin{array}{c}\text { prohibited } \\
\text { work }\end{array}$ & $\begin{array}{c}\text { prohibited } \\
\text { work }\end{array}$ \\
\hline $\begin{array}{l}\text { vibrations acting on underage } \\
\text { workers via upper limbs }(* * *)\end{array}$ & $1 \mathrm{~m} / \mathrm{s}^{2}$ & $4 \mathrm{~m} / \mathrm{s}^{2}$ \\
\hline $\begin{array}{l}\text { whole-body vibrations acting } \\
\text { on underage workers }(* * *)\end{array}$ & $0.25 \mathrm{~m} / \mathrm{s}^{2}$ & $1 \mathrm{~m} / \mathrm{s}^{2}$
\end{tabular}

The regulation by the Minister of Economy and Labour of 5 August 2005 having relevance to work safety in the conditions of noise or vibration exposure gives the threshold levels (specified in Appendixes), i.e. the values of characteristic parameters of noise and vibrations at work (without any personal protection equipment). As regards mechanical vibrations:

- local vibrations: daily exposure expressed as an energy equivalent of $8 \mathrm{~h}$ action of the sum of effective vectors of frequency-weighted acceleration, obtained for the three directional components $\left(a_{h w x}, a_{h w y}, a_{h w z}\right)$ - the threshold level is $2.8 \mathrm{~m} / \mathrm{s}^{2}$,

- whole-body vibrations: daily exposure expressed as an energy equivalent of $8 \mathrm{~h}$ action of the sum of effective vectors of frequency-weighted predominating acceleration, obtained for the three directional components and appropriate weighing coefficients $\left(1.4 a_{w x}, 1.4 a_{w y}, a_{w z}\right)$ - the threshold level is $0.8 \mathrm{~m} / \mathrm{s}^{2}$.

\section{Control object}

Solaris is the trademark of buses, cable cars and coaches manufactured by the Solaris Bus and Coach Company in Środa Wielkopolska, near Poznań (Poland), where the welding plant is located, and in Olechów-Osiedle (finishing works).

First buses Solaris Urbino were designed with the help of German designers from the stylist bureau "IFS Designatelier" from Berlin. In 1999 the low-floor model Solaris Urbino 12 was launched, followed by Solaris Urbino 15 and Solaris Urbino 18. In the year 2000 the smallest model appeared - Solaris Urbino 9. Excellent design and huge customer demand made it a successful brand, which was further developed as new bus models and design options were progressively launched.

There are several design options of Solaris Urbino buses, differing chiefly in the length and load capacity. They are widely used in public transport systems in many Polish towns. 


\section{Methods and procedures}

The measurement procedure was applied in accordance with the relevant standards:

- PN-EN 30326-1 - Mechanical vibrations. Laboratory method of evaluating the seat vibrations in a vehicle. Basic requirements.

- PN-91-N-01352 - Vibrations. Principles of taking measurements at work. (An equivalent of the international standard ISO 2631-1, 1997.)

- PN-ISO 9612 - Acoustics. Guidelines to measurements and assessment of impacts of noise exposure at work.

- PN-EN 60651: 2002 (U) — Sound level measures. General requirements and tests.

- PN-90-S-04052 - Admissible noise level inside vehicles. Requirements and tests.

The acoustic climate inside the buses was investigated in accordance with the approved procedure. On the driver's seat a sensor was mounted to measure seat vibrations in three directions, noise levels were measured with a dosimeter placed in the vicinity of the driver's head. Signals from four channels were analysed in a signal analyser SVAN 948. In the passenger section in the middle part of the vehicle, measurements were taken of floor vibrations and noise levels. In the passengers' section in the rear of the vehicle, measurements were taken of seat vibrations in three directions as well as noise levels. A microphone fitted on a goose neck was placed at the head level.

Relevant correction characteristics had to be applied during the measurements:

- Wk (for the $z$-axis) and Wd (for the $x$ and $y$ axes) - during the vibration acceleration measurements,

- A, C and Linear - in measurements of audible noise.

The averaging time was $1 \mathrm{~s}$ for each sample.

\section{Vibrations and acoustic climate in the bus Solaris Urbino 12 during the ride}

Measurements were taken during the ride of:

- steering wheel vibrations in the driver's cab,

- noise levels inside the driver's cab,

- floor vibrations in the passenger section (middle part),

- noise levels of the passenger section (middle part),

- seat vibrations in the passenger section (rear part),
- noise levels of the passenger section (rear part).

Measuring equipment (type, measuring precision category, manufacturer, manufacturer's symbol):

- SVAN 948, I, SVANTEK, 6549,

- SVAN 948, I, SVANTEK, 6565,

- SVAN 948, I, SVANTEK, 6453.

Measurement procedure: in accordance with the outlined measurement program.

Duration of measurements at point 1 (Driver) $6833 \mathrm{~s}$, at point 2 (Center) - $3225 \mathrm{~s}$, at point 3 (Back) - 6177 or $2595 \mathrm{~s}$. Measurement data are compiled in Tables III and IV and in Figs. 1-10.

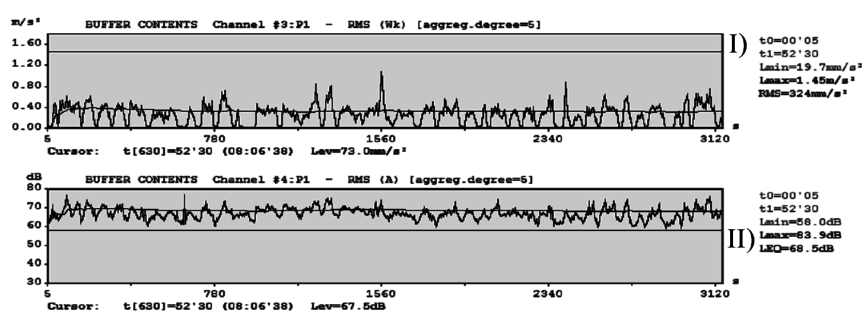

Fig. 1. The driver's cab (I) vibrations, (II) noise levels.

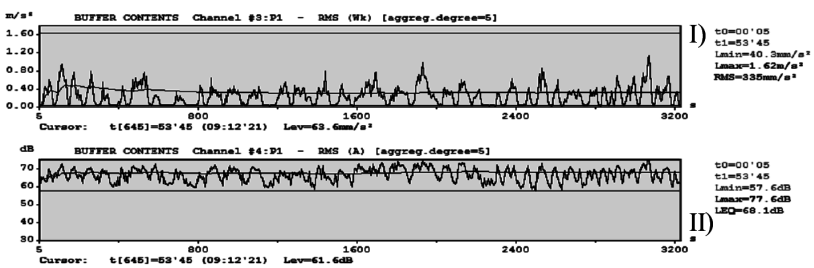

Fig. 2. The passenger section (middle part) (I) vibrations, (II) noise levels.

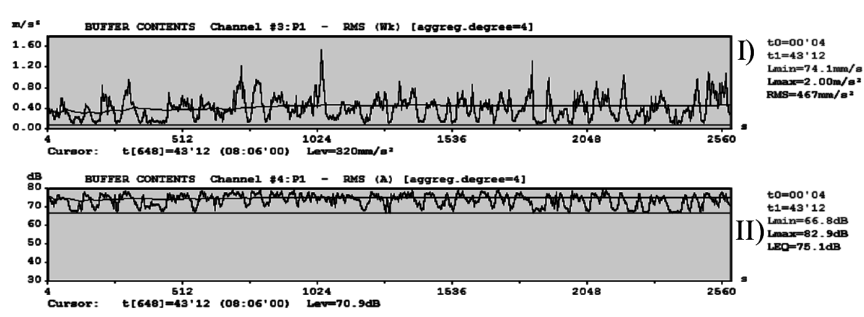

Fig. 3. The passenger section (back part) (I) vibrations, (II) noise levels. 


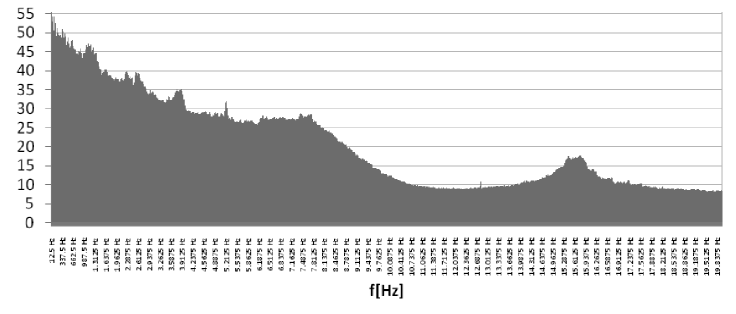

Fig. 4. Spectral analysis $(1-20 \mathrm{kHz})$ of noise inside the driver's cab $[\mathrm{dB}]$.

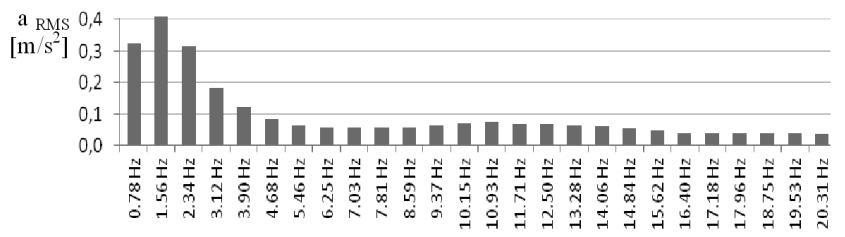

Fig. 5. FFT spectral analysis $(1-20 \mathrm{~Hz})$ of a vibration signal on a vertical dimension in a driver's cab.

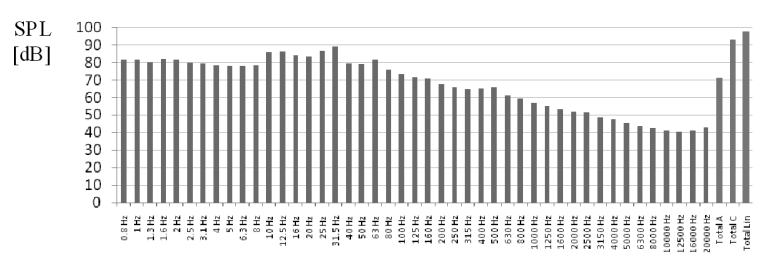

Fig. 6. Spectral analysis of noise inside the passenger section middle part $[\mathrm{dB}]$.

\section{Conclusions}

Test results led us to the following conclusions:

- The lowest values of $a_{w, \text { eq }}$ are registered in the driver's section of a bus, which is associated with the distance from the control point and the vehicle rear part where the engine is located and from the driver's cab where $a_{w, \text { eq }}$ levels tend to be higher than those registered in the middle and back section (Table IV).

- The highest values of weighted accelerations were registered at the end of the passenger section (Table IV), which can be attributable to short distance between the control point and the engine $(\approx 0.5 \mathrm{~m})$, the cooler and other components of the driving system that produce major vibrations.

- Inside the driver's cab the admissible levels of $a_{w, \text { eq }}$ measured on the seat are not exceeded (Fig. 1).

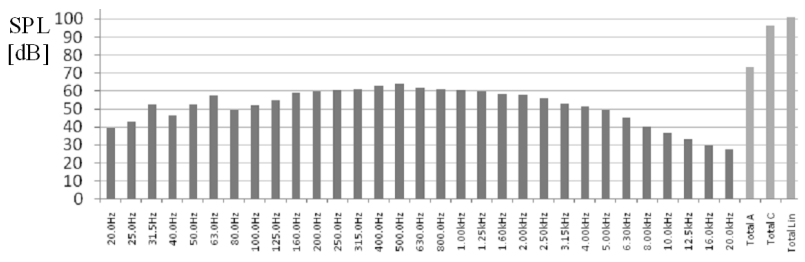

Fig. 7. Spectral analysis of noise inside the passenger section (rear) $[\mathrm{dB}]$.

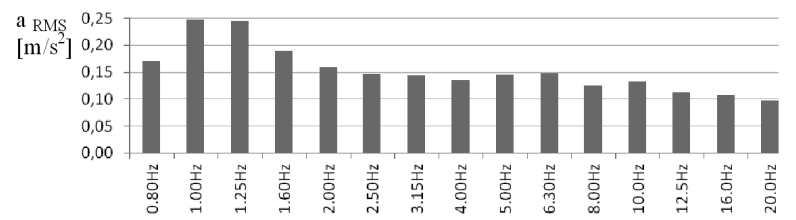

Fig. 8. Spectroanalysis of a vibration signal on a vertical dimension in $1 / 3$ octave frequency bands in the passengers' compartment (back).

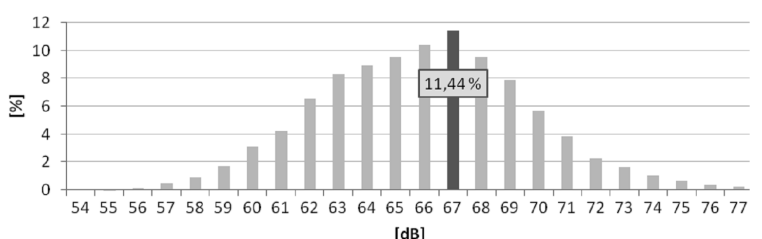

Fig. 9. Histograms of acoustic pressure levels inside the driver's cab.

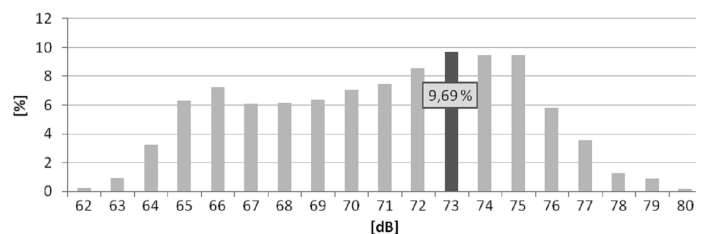

Fig. 10. Histograms of acoustic pressure levels in the passenger section (middle part).

Conditions during the measurements.

TABLE III

\begin{tabular}{l|l}
\hline \hline Date & 29.03 .2008 \\
\hline vehicle model & Solaris Urbino U12 \\
\hline age [in months] & 51 \\
\hline mileage & $416204 \mathrm{~km}$ (on 29.03.2008) \\
\hline measurement period & $07: 14-9: 11$ \\
\hline route length & $43 \mathrm{~km}$ \\
\hline atmospheric conditions & $\begin{array}{l}\text { temp. } 8.4^{\circ} \mathrm{C}, \text { pressure } 989 \mathrm{hPa}, \\
\text { humidity } 66 \%\end{array}$ \\
\hline \multirow{2}{*}{ measurement equipment } & $\begin{array}{l}\text { in the driver's cab: SVAN 948, } \\
\text { in the passenger section: } \\
\text { SVAN 948 }(\times 2), \text { SVAN 945 }\end{array}$
\end{tabular}


TABLE IV

Vibrations and acoustic conditions in the bus Solaris Urbino 12 during the ride.

\begin{tabular}{|c|c|c|c|c|c|c|}
\hline Parameter & Driver & $T[\mathrm{~s}]$ & Center & $T[\mathrm{~s}]$ & Back & $T[\mathrm{~s}]$ \\
\hline$a_{w, \text { eq }}\left[\mathrm{m} / \mathrm{s}^{2}\right]$ & 0.317 & \multirow{5}{*}{6833} & 0.337 & \multirow{5}{*}{3225} & 0.446 & 6177 \\
\hline$L_{\mathrm{Aeq}, \mathrm{T}}[\mathrm{dB}]$ & 68.5 & & 68.1 & & 75.1 & 2595 \\
\hline$L_{\mathrm{A} \max }[\mathrm{dB}]$ & 86.1 & & 77.2 & & 82.9 & 6177 \\
\hline$L_{\mathrm{EX}, 8 \mathrm{~h}}[\mathrm{~dB}]$ & 48.9 & & 58.6 & & 64.6 & 2595 \\
\hline$L_{\mathrm{C} \text { peak }}[\mathrm{dB}]$ & 113.3 & & 115.0 & & 119.0 & 6177 \\
\hline
\end{tabular}

- In a vibration analysis, one may observe an exceedance of the allowed values for minors $\left(>0.25 \mathrm{~m} / \mathrm{s}^{2}\right)$ and pregnant women $\left(>0 \mathrm{~m} / \mathrm{s}^{2}\right.$ - prohibited work) in all measurement points (Table IV).

- The exceedance of the maximum effective vibration weighed value (Table II) was observed in the driver's cab $\left(1.45 \mathrm{~m} / \mathrm{s}^{2}\right)$ (Fig. 1), in the middle $\left(1.62 \mathrm{~m} / \mathrm{s}^{2}\right.$ ) (Fig. 2) and the back section of the passengers' compartment $\left(2 \mathrm{~m} / \mathrm{s}^{2}\right)$ (Fig. 3) for pregnant women and minors.

- In the $1 / 3$ octave analysis in the driver's cab (Fig. 5), the level of vibrations $a_{\mathrm{RMS}}$ exceeds $0.40 \mathrm{~m} / \mathrm{s}^{2}$ for middle frequencies of $1.56 \mathrm{~Hz}$. Similarly in the back section of the vehicle (Fig. 8 ) it exceeds the level of $0.25 \mathrm{~m} / \mathrm{s}^{2}$ for 1.00 and $1.25 \mathrm{~Hz}$.

- In the $1 / 3$ octave analysis, the level of vibrations $a_{\text {RMS }}$ for the entire measurement bandwidth for the middle and rear part of the vehicle is: total $\mathrm{A} \approx$ $70 \mathrm{~dB}$ and total $\mathrm{C} \approx 95 \mathrm{~dB}$ (Figs. 6, 7).

- The highest values of $\mathrm{A}\left(L_{\mathrm{AeqT}}\right)$, the equivalent sound level, were registered in the passenger section, in the driver's and rear part of the vehicle (Table IV).

- The level of $L_{\text {Amax }}$ registered in the driver's cab was higher than in the passenger section in the middle and back part of the vehicle. It appears that the noise level inside the driver's cab is associated with the technical condition of the vehicle and, first of all, with the cab geometry, where the acoustic pressure level is increased. Crucial are also other factors: operation of the control panel, using radio communication systems, using the radio, conversations with passengers - all these contribute to an enhanced equivalent noise level at that point. The largest instantaneous noise levels were registered inside the driver's cab (Table IV).

- In the histogram analysis of acoustic pressure distribution in the driver's cab (Fig. 9), one may ob- serve that the maximum levels $65,66,67$ and $68 \mathrm{~dB}$ contribute in total $\approx 39.6 \%$ of the share.

- In the histogram analysis of acoustic pressure distribution in the midsection of the vehicle (Fig. 10), one may observe that the maximum levels 73,74 and $75 \mathrm{~dB}$ contribute in total $\approx 28 \%$ of the share.

\section{Acknowledgments}

This research program was supported through the author's research grant no. 11.11.130.119.

\section{References}

[1] J.H. Czajka, Measurements of Vibration and Noise at Workplaces in Transport, Warszawa 2000 (in Polish).

[2] Z. Engel, Environment Protection against Vibration and Noise, Warszawa 1993 (in Polish).

[3] A. Eskandarian, R. Sayed, P. Delaigue, J. Blum, A. Mortazavi, Advanced Driver Fatigue Research, Final Report, 09.2003-12.2005 (2007).

[4] W.E. Falou, J. Duchêne, M. Grabisch, D. Hewson, Y. Langeron, F. Lino, Appl. Ergonom. 34, 249 (2003).

[5] I. Hostens, H. Ramon, J. Sound Vibrat. 266, 453 (2003).

[6] A. Kaczmarska, D. Augustyńska, A. Wierzejski, Work Safety 10, 6 (2006) (in Polish).

[7] J. Koton, A. Majewski, Work Safety 7-8, 12 (2004) (in Polish).

[8] M. Kolich, Appl. Ergonom. 34, 177 (2003).

[9] S. Lim, H.S. Choi, M.K. Chung, Int. J. Industr. Ergonom. 35, 1085 (2005).

[10] N. Nawayseh, M.J. Griffin, J. Sound Vibrat. 298, 725 (2006).

[11] O.O., Okunribido, S.J. Shimbles, M. Magnusson, M. Pope, Appl. Ergonom. 38, 29 (2007).

[12] T. Marek, H. Ogińska, J. Pokorski, Transport Ergonomics, Kraków 2001 (in Polish).

[13] A. Markom, N. Hjorth, Occupational Health and Safety in Stall and Medium Construction Companies, Warszawa 2005, p. 104 (in Polish).

[14] K. Tae-Hyeong, K. Young-Tae, Y. Yong-San, Int. J. Industr. Ergonom. 35, 817 (2005).

[15] Z. Damijan, Acta Phys. Pol. A 118, 27 (2010).

[16] Z. Damijan, S. Skrzyniarz, J. Kwaśniewski, Acta Phys. Pol. A 119, 1068 (2011). 